\title{
Personal carbon allowances revisited
}

\author{
Francesco Fuso Nerini $\oplus^{1 凶}$, Tina Fawcett ${ }^{2}$, Yael Parag $\oplus^{3}$ and Paul Ekins ${ }^{4}$
}

\begin{abstract}
Here we discuss how personal carbon allowances (PCAs) could play a role in achieving ambitious climate mitigation targets. We argue that recent advances in Al for sustainable development, together with the need for a low-carbon recovery from the COVID-19 crisis, open a new window of opportunity for PCAs. Furthermore, we present design principles based on the Sustainable Development Goals for the future adoption of PCAs. We conclude that PCAs could be trialled in selected climate-conscious technologically advanced countries, mindful of potential issues around integration into the current policy mix, privacy concerns and distributional impacts.
\end{abstract}

$\mathrm{C}$ limate change could undermine the achievement of at least 72 Targets across the Sustainable Development Goals (SDGs) ${ }^{1}$. The development of a just and equitable transition to a net-zero society is vital to avoiding the worst impacts of climate change ${ }^{1}$. However, by May 2021, Climate Action Tracker $^{2}$ estimated that climate policies implemented across the world at present, including the effect of the pandemic, will lead to a temperature rise of $2.9^{\circ} \mathrm{C}$ by the end of the century. Thus, although many countries have made pledges of net-zero emissions by 2050, implemented policies and pledges are insufficient to deliver the Paris Agreement ambition of limiting global warming to well below $2{ }^{\circ} \mathrm{C}\left(\right.$ ref. $\left.^{3}\right)$. To take a national example, the United Kingdom has made strong progress in reducing carbon emissions, and was an early adopter of a net-zero by 2050 target. However, the government's independent advisory climate body advises that policy steps taken so far "do not yet measure up to meet the size of the net-zero challenge ${ }^{\text {"4 }}$.

In this context, the introduction of personal carbon allowances (PCAs), a mitigation policy proposal developed in the $1990 \mathrm{~s}^{5}$, is ripe for revisitation. This policy aims to link personal action with global carbon reduction goals. A PCA scheme would entail all adults receiving an equal, tradable carbon allowance that reduces over time in line with national targets. In its original design, the allowance could cover around $40 \%$ of energy-related carbon emissions in high-income countries, encompassing individuals' carbon emissions relating to travel, space heating, water heating and electricity ${ }^{6}$. Allowances were envisioned to be deducted from the personal budget with every payment for transport fuel, home-heating fuels and electricity bills. People in shortage would be able to purchase additional units in the personal carbon market from those with excess to sell. New, more ambitious PCA proposals include economy-wide emissions, encompassing food, services and consumption-related carbon emissions ${ }^{7}$, for example.

Several variations of mandatory PCAs or personal carbon-trading schemes have been proposed in the literature under different names ${ }^{8}$. For instance, centrally allocated and tradable PCAs have been examined by the UK government, looking at a design covering household energy and personal travel ${ }^{9}$. Electronic Tradable Energy Quotas (TEQs) were also proposed in the United Kingdom, covering the whole economy and divided among individuals (40\%) and other energy users $(60 \%)^{10}$. In Ireland, cap and share certificates covering the whole economy were proposed, giving all adults emission certificates for an equal share of national emissions. Such certificates were proposed to be sold by individuals via banks and post offices to fossil fuel companies ${ }^{11}$. In California, household carbon trading was proposed for household energy, and managed by the utilities ${ }^{12}$. In France, centrally managed tradable transport carbon permits were assessed related to private transport ${ }^{13}$. Scholars from the University of Groningen have proposed European Union (EU)-wide emissions trading for households and transport, embedded in the EU Emissions Trading Scheme (ETS) design. In this design, free carbon allowances are allocated to each category of small emitters on the basis of their historic emissions (grandfathering), then surrendered with the purchase of energy from distributors, which in turn give them up as they obtain fuel from fuel producers and importers, who then have to match with allowances their supply of fuel ${ }^{14}$. Furthermore, tradable consumption quotas have been proposed to cover all consumption emissions related to manufacturing processes $^{15}$. The mandatory nation-wide designs described above are complemented by voluntary schemes, some of which have been trialled in several locations.

The literature highlights the importance of economic incentives, cognitive awareness, prevailing social norms and education as drivers for pro-environmental decision-making and behaviour ${ }^{16,17}$. Research indicates that behavioural change could be engendered by creating a direct and visible incentive to reduce carbon emissions ${ }^{14,18}$. Studies show that people tend to adhere to the prevailing norm and that descriptive social norms and comparison with others influence decisions about electricity use ${ }^{19,20}$ and mode of transport $^{21}$. Building on this literature, PCAs are envisaged to deliver carbon-emissions-related behavioural change via three interlinked mechanisms: economic, cognitive and social ${ }^{22}$ (Fig. 1). Similar to a carbon tax, a policy with which it is often compared, the economic mechanism of PCAs is envisaged to influence decision-making by assigning a visible carbon price to the purchase and use of fossil-fuel-based energy in the first instance, and possibly also to consumption-related emissions in more advanced PCA designs. However, in addition to the economic mechanism, PCAs aim to influence energy and consumption behaviour by increasing carbon visibility, by evoking users' cognitive awareness of carbon in their daily routines and by encouraging carbon budgeting. Moreover, the shared goal of emissions reduction and the equal-per-capita allocation of PCAs is envisaged to create a social norm of low-carbon behaviour. These three interlinked mechanisms are hypothesized to promote low-carbon lifestyles in a synergetic manner.

${ }^{1} \mathrm{KTH}$ Climate Action Centre \& KTH division of Energy Systems, School of Industrial Engineering and Management, KTH Royal Institute of Technology, Stockholm, Sweden. ${ }^{2}$ Environmental Change Institute, University of Oxford, Oxford, UK. ${ }^{3}$ School of Sustainability, Interdisciplinary Center Herzliya, Herzliya, Israel. ${ }^{4}$ Institute for Sustainable Resources, University College London, London, UK. 凶e-mail: francesco.fusonerini@energy.kth.se 


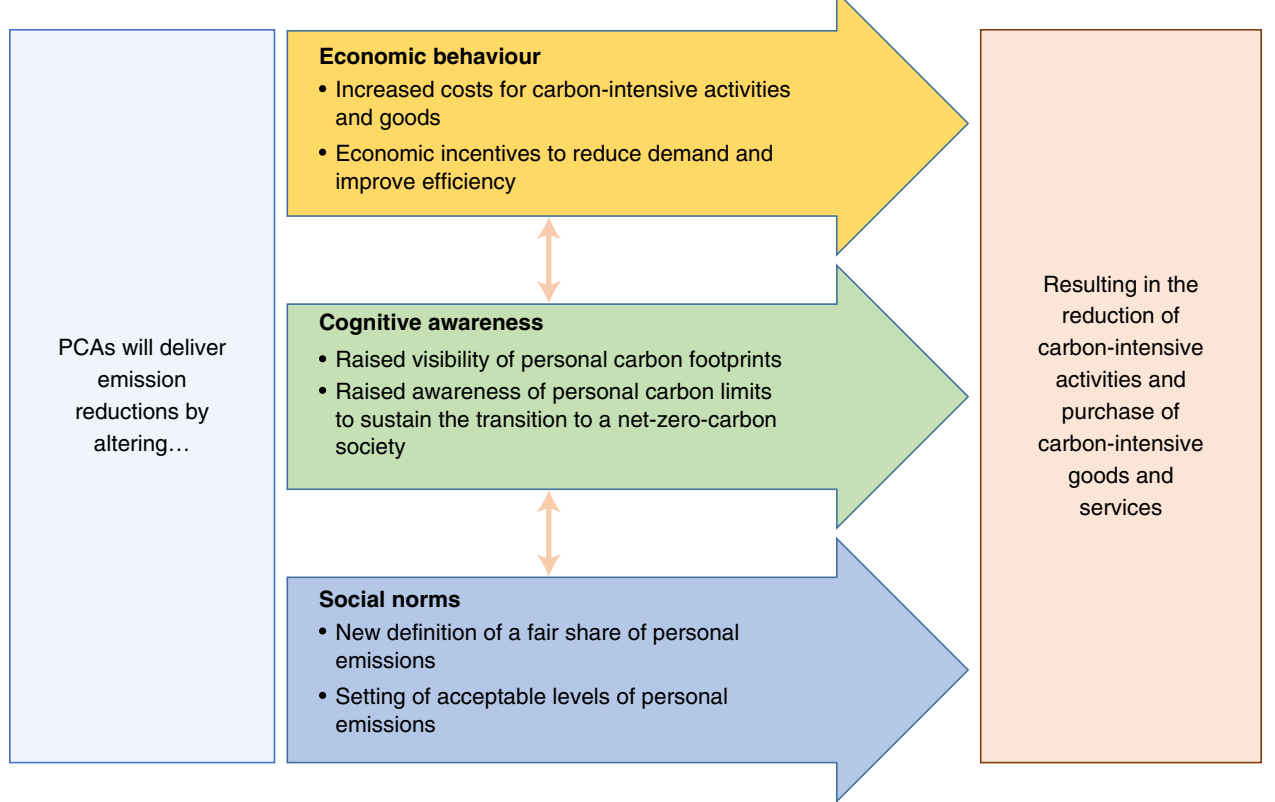

Fig. 1 | PCA influence mechanisms for delivering emission reductions. Key mechanisms through which PCAs encourage and promote a low-carbon lifestyle. Adapted from Parag and Strickland ${ }^{64}$.

Furthermore, end-user emission cap-and-trade schemes have been described in the literature as a means to rationalize individual engagement in sustainability activities, regulate voluntary offset markets, cap uncapped sectors such as the residential and transport sectors, and stimulate energy-efficiency interventions ${ }^{7}$.

In the 2000s, when the UK government explored the adoption of PCA scheme to reduce carbon emissions from households, the idea was rejected due to claimed low social acceptability, technological barriers and high implementation costs ${ }^{8,9,23}$. PCAs were defined in the early 2010s as "a big idea that never took off" 24 , and "'a policy ahead of its time" ${ }^{5,9}$. No large-scale national programmes have so far investigated PCAs as a policy option. By 2021, arguably, the policy window of opportunity provided by the COVID-19 cri$\operatorname{sis}^{25}$, in combination with the need to address worsening climate and biodiversity crises ${ }^{26}$, and by the advancements in information and communication technologies, particularly artificial intelligence $(\mathrm{AI})^{27}$, could improve the feasibility and attractiveness of PCAs to policymakers and the public.

The purpose of this Perspective is not to advocate for the widespread adoption of PCAs, but rather to restart a science and policy dialogue on a policy option that could help achieve climate mitigation goals by re-evaluating the attractiveness of PCA schemes in the 2020 s and beyond. We first analyse the barriers that were recognized a decade ago to the widespread adoption of PCAs and reflect on recent social and technical changes that may increase the appeal of PCA schemes in the 2020s. We then develop SDG-based design principles for guiding future applications of PCAs, and present recommendations for the future exploration of PCAs. In our evaluation we are not referring to any specific PCA design; we consider PCAs as a national mandatory policy, with diverse potential designs depending on the local context. To limit the boundaries of this Perspective, PCAs are assessed here as a scheme for more developed countries-those with high per-capita emissions and the administrative capability to implement such policies.

\section{Barriers to the adoption of PCAs}

In 2008, after concluding that involving households was critical to reach climate goals ${ }^{28}$, the UK government commissioned a pre-feasibility study on PCAs. The study, developed by the Department for Environment, Food and Rural Affairs (DEFRA), investigated the effects of a mandatory household-level scheme with free equal-per-capita carbon credits for all UK adults. The study highlighted some substantial challenges with PCAs, which resulted in PCAs and trading being characterized as an "idea ahead of its time" . Starting from that landmark assessment, and adding analysis from the subsequent literature, we identify the main barriers to the adoption of PCAs.

Political resistance and crowded policy landscapes. As mentioned above, at the time of consideration in the United Kingdom, PCAs were considered a radical approach for mitigation. This is still true: PCAs have been described as radical in more recent literature ${ }^{29}$. There are clear political risks in advocating for challenging or radical policies, particularly if they have never been implemented elsewhere and there is no previous policy experience to learn from. Aside from the United Kingdom's early interest, no European country has expressed clear political interest in examining, let alone adopting, $\mathrm{PCAs}^{7}$. Furthermore, existing climate and energy policies may be perceived as creating a barrier to the inclusion of PCAs. In particular, some argue that PCAs as a downstream measure combined with the existing EU ETS could result in double-pricing of certain emissions, if not properly planned ${ }^{7,14,30}$. Although the need for a combination of policy instruments to address the multiple market failures that have led to the excessive generation of environmental pollutants has long been recognized in the literature ${ }^{31}$, and a policy mix is a normal characteristic of policy landscapes ${ }^{32}$, incorporating a radical policy that has never been implemented before into an existing policy landscape is nevertheless risky, and therefore challenging for politicians.

Technological barriers and high implementation costs. A key question about PCAs is how could they be implemented in practice? What technology is needed to manage carbon accounts? How will people keep track of their carbon allowances? And how would allowances be traded? In the 2000s, the vision was of carbon accounts, analogous to bank accounts, and a carbon card to which 
allowances would be charged and from which deductions would be made. This option was chosen as it was the most suitable given the existing technological capabilities and was perceived as the most appropriate for a public that was not very 'carbon capable ${ }^{33}$. However, surveys indicated that the proposed system was perceived by the public as challenging and complex ${ }^{9}$. The DEFRA 2008 study evaluated and costed the option of assigning carbon credits in a national account system run by private sector organizations such as banks ${ }^{9}$. Costs were higher than other mitigation policy measures, such as the United Kingdom's Climate Change Agreements ${ }^{9}$. Although lower cost estimations than the one in the 2008 DEFRA report for PCAs existed, all were higher than the cost of upstream schemes, mostly due to high administrative costs ${ }^{30}$. As a result, it was concluded that significant cost reductions would be needed for PCAs to be economically feasible. As discussed later, advances in technology and increased awareness of carbon and climate change mean there are now different options available.

Low social acceptability. From its inception, there have been concerns about the social acceptability of PCAs and their potential to result in unfair distributional effects. Social acceptability was investigated by applying a range of methods including interviews, focus groups, questionnaires, choice experiments and modelling ${ }^{8}$. When the public perception of PCAs was evaluated through interviews in the United Kingdom in 2008, opinions ranged from quite positive to negative ${ }^{9}$. While interviewees were generally willing to accept some responsibility over their emissions, the perceived complexity and the central control over people's activities were identified as key challenges ${ }^{9}$. Furthermore, surveys in other contexts suggest that the perceived complexity of a PCA scheme could limit its public acceptability $^{34}$.

Distributional impacts. Another factor that influences the social acceptability of PCAs is the need for them to be perceived as fair, such that certain groups are not being disproportionately affected. When a PCA scheme was evaluated in the United Kingdom in the 2000s, $71 \%$ of low-income households were identified as 'winners' and $55 \%$ of high-income households 'losers' from the policy'. In other words, due to the variation in energy use, most low-income households were likely to have more allowances than needed to cover their energy needs, and hence could sell excess allowances for money (winners), whereas most high-income households were likely to have fewer allowances relative to their energy needs, and therefore would need to buy extra units in the market (losers). However, a small percentage of low-income loser households were also identified, most of which were living in rural areas ${ }^{9}$. Public perceptions of fairness, as well as the distributional effects of PCAs, depend on how fairness is defined ${ }^{35}$, on the detailed design of the PCAs scheme and on any associated compensatory policies.

\section{A changing landscape for PCAs}

Visible negative effects of the escalating climate and biodiversity crises on many sustainable development issues ${ }^{1,36}$ have led to increased public concern over climate change, particularly by the young, as shown in the Fridays for Future movement and climate strikes around the globe. The global climate strike of 2019 was one of the largest events organized by environmental social movements so $\mathrm{far}^{37}$. Recent evidence shows the significant impact of wide participation in these protests on political responsiveness, and on the dissatisfaction with current climate action among young adults and their families ${ }^{38,39}$. Mounting public pressure may have played a part in the increasing number of countries and regions including the EU, the United States, the United Kingdom and China that by 2021 had presented pledges to have net-zero carbon emissions by 2050 or 2060. To achieve such pledges, mitigation policies have been put in place to reduce emissions through a wide array of interventions and programmes. However, as both energy and carbon are invisible, it remains difficult for individuals to estimate the contribution of their lifestyles and activities to the nations' emissions. While energy prices contain some costs related to carbon (for example, the EU ETS, to the extent that this is passed on to energy consum$\left.e r s^{40}\right)$, and this may be expected to have some impact on consumers' decision-making, the large participation in social movements demonstrates that many individuals also consider themselves as citizens with responsibilities to the environment and future generations. To this extent, PCAs may be effective as a 'symbolic policy' - a practical measure that encapsulates a vision or story about a wider change, and signals and engages citizens in this wider vision and project ${ }^{41}$. If that is a good description of PCAs, then the route to political acceptability may be to show that it can deliver both practical and symbolic benefits. Given the public demand for more ambitious action and the political commitment to ambitious targets, PCAs could be of increased public and political interest.

PCAs should also be re-evaluated in the context of the COVID-19 experience and lessons that are being learned. Recent research has shown the pervasive negative effects of the pandemic on almost $90 \%$ of the SDG targets ${ }^{25}$ - drawing a strong parallel to the climate crisis, which in different ways may negatively influence a similar number of SDG targets ${ }^{1}$. It was estimated that a low-carbon pandemic recovery could reduce carbon emissions in 2030 by $25 \%$ compared with pre-COVID-19 projections ${ }^{42}$. The aspiration of the international community for a 'sustainable recovery' from the COVID-19 pandemic, combined with heightened awareness of the effect of individuals' actions on the spread of the pandemic, the global connectivity that means that people everywhere are affected by global problems, and the new behavioural and social norms formed during the pandemic, may favour PCAs.

In particular, during the COVID-19 pandemic, restrictions on individuals for the sake of public health, and forms of individual accountability and responsibility that were unthinkable only one year before, have been adopted by millions of people. People may be more prepared to accept the tracking and limitations related to PCAs to achieve a safer climate and the many other benefits (for example, reduced air pollution and improved public health) associated with addressing the climate crisis. Other lessons that could be drawn relate to the public acceptance in some countries of additional surveillance and control in exchange for greater safety. For instance, in many countries, mobile apps designed for COVID-19 infection tracking and tracing played an important part in limiting the spread of the pandemic. The deployment and testing of such apps provide technology advances and insights for the design of future apps for tracking personal emissions. Recent studies show how COVID-19 contact-tracing apps were successfully implemented with mandatory schemes in several East Asian countries, such as China, Taiwan and South Korea ${ }^{43}$. In these countries, the apps assessed each user's travel history and health status, playing a key role in tracking infections ${ }^{43}$. These unique natural experiments give insights into possible strategies to use apps to track PCAs. For instance, the many digital contact-tracing algorithms that were developed and tested ${ }^{43,44}$ provide initial valuable information for the design of future apps that-for example-estimate emissions on the basis of tracking the user's movement history. However, the adoption of such apps also raised issues regarding the balance between data privacy concerns and public health ${ }^{45}$. A recent review showed that only 16 of 50 reviewed contact-tracing apps explicitly state that the user's data will be made anonymous, encrypted and secured and reported only in an aggregated format ${ }^{46}$. Such a balance is also perceived differently in diverse countries. Initial evidence points to various issues related to adopting such schemes in liberal democracies such as in Europe and the United States-where data privacy, trust and ethical issues strongly limited participation in contact-tracing efforts during the COVID-19 pandemic ${ }^{46}$. Such resistance itself also 


\begin{tabular}{|c|c|}
\hline Recognized barriers to PCA adoption in recent decades & Changes to overcome barriers in the 2020 s \\
\hline \multirow[t]{3}{*}{ Political resistance and crowded policy landscapes } & - Recognized urgency to act on climate and biodiversity crises \\
\hline & - Calls for low-carbon recovery from COVID-19 \\
\hline & $\begin{array}{l}\text { - Need for innovative policy mixes effectively addressing personal behaviours to achieve } \\
\text { net-zero carbon pledges }\end{array}$ \\
\hline \multirow[t]{4}{*}{ Technological barriers and high implementation costs } & - Recent Al advances reduce technological barriers and implementation costs \\
\hline & - Very high ownership of smartphones can ease implementation \\
\hline & - Al advances to provide individualized advice on behaviour change options \\
\hline & - Technology-related lessons learned from COVID-19 tracking \\
\hline \multirow[t]{3}{*}{ Low social acceptability and distributional impact } & - Public awareness of the climate crisis \\
\hline & - Social movements for climate action \\
\hline & $\begin{array}{l}\text { - Understanding the impact of individual actions on the public good, as a result of } \\
\text { COVID-19 }\end{array}$ \\
\hline
\end{tabular}

Actions to avoid distributional impacts are discussed more in detail in the sections below. Barriers are from ref. ${ }^{8}$.

provides important lessons for future PCA-tracking apps. For instance, new regulations have been suggested to address data privacy concerns and security vulnerabilities when using these apps $^{43}$ and significant technological advances were made for privacy-preserving contact-tracing apps ${ }^{44}$. These advances could help pave the way for the adoption of PCA schemes. However, citizen engagement and participatory approaches would be needed to design and implement PCA schemes that balance personal liberties with delivering climate aims in a socially acceptable manner.

Finally, advances in digitalization and AI for sustainable development $^{27}$ promise to shrink implementation costs and logistical challenges for PCAs-and to improve personalized feedback, information and advice. Recent advances in smarter home and transport options make it possible to easily track and manage a large share of individuals' emissions. Evidence from the roll-out of smart meters and informative displays can be used to design feedback that is highly effective in engaging individuals to reduce their energy-related emissions ${ }^{47}$. Furthermore, AI breakthroughs combined with very high ownership of smartphones will allow the low-cost development of new personalized apps to account for PCAs and trade personal emissions. For instance, machine-learning algorithms could be trained to automatically gather all the available information on someone's emissions, and to fill data gaps and accurately estimate an individual's carbon emissions on the basis of limited data inputs such as stops at petrol stations, check-ins at venues and travel histories. AI could be especially beneficial for PCA designs that also include food- and consumption-related emissions. Many voluntary smartphone apps can already capture personal travel and dietary behaviours for estimating carbon emissions and potential health consequences. Algorithms in those apps can intelligently understand the mode of transport on the basis of the user's speed and trajectory, and can estimate food-related emissions on the basis of purchasing habits ${ }^{48}$. More importantly, machine learning could also support our understanding of what information and advice are most effective for promoting behaviour change through PCAs. An ever-increasing number of decision-making tasks are being delegated to software systems ${ }^{49}$, allowing the presentation of targeted personalized information to future users on their emissions patterns. The latest science on AI for learning, including the use of virtual agents ${ }^{50,51}$, could help refine the type of information that users are shown to manage and reduce their carbon emissions. To the user, all of the above could be packaged in an easy-to-use smartphone app that presents tailored information and advice on personal carbon emissions and facilitates carbon savings.
Given the above, the adoption of PCA schemes to support climate action in the 2020s does not seem as challenging to implement $^{5}$ as it did previously (Table 1 ).

\section{Sustainable design of PCAs}

Informed by recent methods assessing SDGs interlinkages ${ }^{1,27,52}$, Table 2 explores how PCAs could interact with outcomes in various SDGs, to provide information for their future design.

\section{The way forwards to sustainable PCAs}

Adopting PCAs at scale in any given region or country will be a challenging research and policy task. It is unlikely that the same PCAs design would work everywhere-or that PCAs are a suitable policy for all regions or countries ${ }^{53}$. Climate-ambitious technologically advanced countries with high trust in the government would potentially have more success in implementing just and equality-based PCAs. Such countries would have to investigate how PCAs could be designed to work in their specific social, economic and geographical context, and how such a policy could be practically implemented and harmonized with existing climate policies ${ }^{1,54}$ to reduce the risk of incompatibilities ${ }^{55,56}$. Nevertheless, scholars argue that existing policies are unlikely to be effective in meeting emission targets ${ }^{57}$ and therefore policymakers should use the full range of instruments ${ }^{58}$. In the EU, insight could be gained from the way the EU ETS is linked to offset markets such as certified emission reductions and the Clean Development Mechanism ${ }^{7}$, and from proposals on how to harmonize PCAs with the EU ETS scheme ${ }^{14}$. This Perspective does not present an analysis of how PCAs would cohere with existing policy mixes; this analysis would need to be done at national level before implementation.

In terms of implementation platforms, while in the 2000s carbon allowances were expected to be managed by a card, in the 2020 s high ownership would make smartphones the preferred option for accounting and trading (while providing alternative options for the few without smartphones). Innovative AI and machine-learning capabilities would facilitate the expansion of PCAs to include embedded emissions in goods and services, which are harder to calculate, and could help in providing individuals with tailored and timely advice on how to reduce their lifestyle emissions.

The SDG-based design principles for PCAs in Table 2 give an overview of the potential benefits, as well as challenges, that policymakers considering PCAs may encounter. PCAs could be designed to encompass only certain emissions (such as travel, or the household use of fossil fuel methane for heating) or be more comprehensive and cover the whole economy (for example, including all 


\section{Table 2 | SDG-based design principles for future PCA applications}

SDG 1 No poverty

SDG 2 Zero hunger

SDG 3 Good health and well-being

SDG 4 Quality education

SDG 5 Equality

SDG 6 Clean water and sanitation

SDG 7 Affordable and clean energy

SDG 8 Decent work and economic growth

SDG 9 Industry, innovation and infrastructure

SDG 10 Reduced inequality

SDG 11 Sustainable cities and communities

SDG 12 Responsible consumption and production

SDG 13 Climate action

SDG 14 Life below water

SDG 15 Life on land

SDG 16 Peace and justice strong institutions

SDG 17 Partnerships to achieve the goal
PCAs must be designed in a way that will not negatively impact poor and vulnerable populations. In principle, PCAs support redistribution as, on average, rich populations emit more than poor populations. Targeted protection for vulnerable loser ${ }^{59}$ should be provided in parallel policy provisions.

Current PCA designs do not include food-related emissions, as incomplete carbon tracking in food production does not yet allow this. The future inclusion of food-related emissions in PCAs could increase consumer demand for more sustainable food production (Target 2.4) ${ }^{7}$. However, care must be taken to ensure that greenhouse gas savings are aligned with broader sustainability goals in food systems.

PCAs could potentially promote healthier lifestyles-primarily by favouring active travel such as walking and cycling, and healthier diets. Furthermore, PCAs could be combined and harmonized with local policies to address air pollution in populated areas. A transfer of resources to lower-income households through PCAs should also help reduce energy poverty, thereby reducing its associated detrimental effect on health ${ }^{59}$.

PCAs are associated with increased knowledge about the multiple benefits of low-carbon and sustainable lifestyles. Large-scale adoption of PCAs should go hand-in-hand with the generation of such knowledge and the dissemination of skills needed to promote sustainable development as detailed in Target 4.7.

PCAs would entail equal carbon allowances among genders. However, ongoing evaluation of the effects of trading emissions on equality outcomes would be required (to manage the risk of trading leading to unforeseen gender inequalities).

At the residential level, water-use efficiency (Target 6.4) would reduce water-related energy use and carbon emissions. This may be particularly relevant as water carbon footprints increase, with water supply being more reliant on desalination in water-scarce countries. To achieve this synergy, information campaigns will need to inform the public about the water-energy nexus. At the same time, there is a risk that PCAs will increase the price of drinking water in certain regions.

PCAs would go hand-in-hand with this goal and support the transition to clean energy while reducing emissions and improving health and environmental sustainability. For instance, householders could install renewable energy capacity in their property and improve the building's energy efficiency (Targets 7.2 and 7.3) to contribute to reducing personal carbon emissions. However, PCA designs will need to take into account energy affordability (7.1) - this links with design considerations to meet SDG1.

PCAs can help deliver green growth, with opportunities for high-quality employment and opening new markets associated to trading allowances. However, it may reduce growth in high-carbon sectors (while promoting growth and jobs in lower-carbon sectors). Any PCA design should assess the potential negative impacts on high-carbon sectors, and evaluate support schemes for affected people and regions.

PCAs will support low-carbon infrastructure and innovation, opening up room for new businesses and technologies to support decreasing personal emissions. However, high-carbon industries may be adversely affected and consideration of these economic sectors will be crucial to informing the targeting of complementary economic policy.

PCAs based on equal-per-capita allowances would be progressive in all contexts where higher-income groups have higher emissions. Modelling in the United Kingdom, China and Finland has demonstrated that proposed PCA schemes in these countries would be progressive ${ }^{61-63}$, thus reducing inequalities. However, there will be certain lower-income/ vulnerable households with high carbon emissions who will be losers under PCAs. Compensation and support that are tailored to the needs of these vulnerable groups will be needed to support their transition to lower-carbon living.

PCAs could support several of the targets in SDG11, by potentially promoting sustainable urbanization (Target 11.3) and transportation (Target 11.2). The network of sensors that could be used to track emissions, such as smart meters and intelligent houses, would support the development of smart cities. As for SDG3, PCAs could be designed in conjunction with efforts to address cities' air pollution.

PCA designs should take into account how individuals could use sustainable consumption practices to decrease their carbon emissions. This would be especially relevant with PCA designs including embedded emissions in goods and services.

The adoption of PCA-like policies will need to be harmonized with other climate mitigation and adaptation policies', and consider path dependency and possible friction in the current policy landscape ${ }^{54}$.

PCA designs will need to consider whether activities to reduce and trade personal emissions could negatively affect aquatic ecosystems or human activities related to those ecosystems. Potentially, if food-related emissions are included in PCAs, it is likely that people will reduce their meat consumption and partially replace it with fish. In that case, PCA designs should evaluate the effect on the policy on the achievement of SDG14.

PCA designs will need to consider whether activities to reduce and trade personal emissions could negatively affect terrestrial ecosystems or human activities related to those ecosystems. Potentially, if food-related emissions are included in PCAs, it is likely that high-carbon foods, which on average use more land per calorie provided, will be less favoured. And it may be that PCAs could be integrated with land-based carbon sequestration schemes, once robust carbon accounting, monitoring, verification and reporting of such schemes have been developed.

PCAs, by design, will enable greater citizen engagement and participatory processes (Target 16.7). However, PCA designs will need to consider whether and how the adoption of PCAs could result in new social disputes that could undermine local peace and/or trust in social institutions.

Whereas PCAs as discussed here are a proposed national policy option for high-income countries, future designs could investigate whether international trading of emissions could be used as a mean to mobilize additional resources to help developing countries to reduce carbon emissions. 
household direct and indirect emissions such as food- and other consumption-related emissions). Therefore, positive and negative impacts on the SDGs are likely to vary significantly.

Possible negative impacts of PCAs on vulnerable consumers will need to be carefully assessed to avoid situations in which they are negatively affected and do not have the means to change their emissions. The design of PCAs should strive to be fair, while acknowledging that it is not possible to have a policy with no losers. In particular, as people vary in their energy needs, an equal-per-capita allowance is not necessarily fair ${ }^{9}$, even if overall PCAs significantly reduce income inequality. Country-specific compensation ${ }^{59}$ or additional policies (for example, initiatives to tackle under-occupancy or improve thermal performance in rural homes) are likely to be needed for some vulnerable loser groups ${ }^{9}$.

Technology-enabled PCA designs will need to consider issues around privacy, cybersecurity and digital ethics. Some lessons from the loss of privacy associated with the use of tracking apps during the COVID-19 pandemic ${ }^{46}$ could provide initial insights into ethical and secure app design ${ }^{60}$ (for example, new regulations and new algorithms for privacy-preserving apps ${ }^{44,45}$ ).

The research community will need to step up to support a more detailed investigation of carbon allowances. Voluntary PCA initiatives and PCA-like schemes will be essential to trial various designs. Evidence from those trials should be incorporated into models that evaluate the impacts of various designs on different income groups. Participatory research methods and engagement with a wide range of stakeholders could help to advance the knowledge of this policy option.

With the world not on track to meet the objectives of the Paris Agreement using current policy tools, PCAs might offer a new approach. Although a PCA scheme would not be easy to design or implement, given the need for very ambitious reduction targets, climate-ambitious countries should ask: if not PCAs, what other scheme should be put in place to affect high-carbon behaviours in support of the objective of net-zero carbon emissions?

Received: 15 March 2021; Accepted: 7 July 2021;

Published online: 16 August 2021

\section{References}

1. Fuso Nerini, F. et al. Connecting climate action with other Sustainable Development Goals. Nat. Sustain. 2, 674-680 (2019).

2. Warming Projections Gobal Update (Climate Action Tracker, 2021); https://climateactiontracker.org/publications/global-update-climatesummit-momentum/

3. IEA World Energy Outlook 2020 (OECD, 2020); https://doi.org/10.1787/ 557a761b-en

4. Reducing UK Emissions: 2020 Progress Report to Parliament (UK Climate Change Committee, 2020); https://www.theccc.org.uk/publication/reducinguk-emissions-2020-progress-report-to-parliament/

5. Fawcett, T. Personal carbon trading: a policy ahead of its time? Energy Policy 38, 6868-6876 (2010).

6. Fawcett, T. \& Parag, Y. An introduction to personal carbon trading. Clim. Policy 10, 329-338 (2010).

7. Suryapratim, R. Situating the Individual Within a Behavioural Law and Economics Approach to End-User. Doctoral thesis, Univ. Groningen (2017).

8. Parag, Y. \& Fawcett, T. Personal carbon trading: a review of research evidence and real-world experience of a radical idea. Energy Emiss. Control Technol. 2, 23-32 (2014).

9. Synthesis Report on the Findings from Defra's Pre-Feasibility Study into Personal Carbon Trading (DEFRA, 2008).

10. Fleming, D. Energy and the Common Purpose: Descending the Energy Staircase with Tradable Energy Quotas (TEQs) (The Lean Economy Connection, 2007).

11. Cap and Share-A Fair Way to Cut Greenhouse Emissions (FEASTA, 2008); https://www.feasta.org/2008/05/29/cap-and-share-a-fair-way-to-cutgreenhouse-emissions/

12. Niemeier, D. et al. Rethinking downstream regulation: California's opportunity to engage households in reducing greenhouse gases. Energy Policy 36, 3436-3447 (2008).

13. Raux, C. \& Marlot, G. A system of tradable $\mathrm{CO}_{2}$ permits applied to fuel consumption by motorists. Transp. Policy 12, 255-265 (2005)
14. Woerdman, E. \& Bolderdijk, J. W. Emissions trading for households? A behavioral law and economics perspective. Eur. J. Law Econ. 44, 553-578 (2017).

15. Ayres, R. U. Environmental market failures: are there any local market-based corrective mechanisms for global problems? Mitig. Adapt. Strateg. Glob. Change 1, 289-309 (1997).

16. Chatterton, T. An Introduction to Thinking about 'Energy Behaviour': A Multi Model Approach (Department of Energy and Climate Change, 2011); https:/www.gov.uk/government/publications/thinking-about-energy-behaviour a-multi-model-approach

17. Darby, S. Literature Review for the Energy Demand Research Project (Environmental Change Institute, Univ. Oxford, 2010).

18. Zanni, A. M., Bristow, A. L. \& Wardman, M. The potential behavioural effect of personal carbon trading: results from an experimental survey. J. Environ. Econ. Policy 2, 222-243 (2013).

19. Bator, R. J., Tabanico, J. J., Walton, M. L. \& Schultz, P. W. Promoting energy conservation with implied norms and explicit messages. Soc. Influ. 9, 69-82 (2014).

20. Schultz, P. W., Nolan, J. M., Cialdini, R. B., Goldstein, N. J. \& Griskevicius, V. The constructive, destructive, and reconstructive power of social norms: research article. Psychol. Sci. 18, 429-434 (2007).

21. Kormos, C., Gifford, R. \& Brown, E. The influence of descriptive social norm information on sustainable transportation behavior: a field experiment. Environ. Behav. 47, 479-501 (2015).

22. Parag, Y., Capstick, S. \& Poortinga, W. Policy attribute framing: a comparison between three policy instruments for personal emissions reduction. J. Policy Anal. Manage. 30, 889-905 (2011).

23. Parag, Y. \& Eyre, N. Barriers to personal carbon trading in the policy arena. Clim. Policy 10, 353-368 (2010).

24. Corner, A. Personal carbon allowances-a 'big idea that never took off'. The Guardian https://www.theguardian.com/sustainable-business/personalcarbon-allowances-budgets (30 April 2012)

25. Fuso Nerini, F., Swain, A. \& Swain, R. B. Sustainable development in the wake of COVID-19. Preprint at ResearchSquare https://doi.org/10.21203/ rs.3.rs-63414/v1 (2020).

26. Shan, Y. et al. Impacts of COVID-19 and fiscal stimuli on global emissions and the Paris Agreement. Nat. Clim. Change 11, 200-206 (2020).

27. Vinuesa, R. et al. The role of artificial intelligence in achieving the Sustainable Development Goals. Nat.Commun. 11, 233 (2020).

28. Personal Carbon Trading-Fifth Report of Session 2007-08 (UK House of Commons Environmental Audit Committee, 2008); https://publications. parliament.uk/pa/cm200708/cmselect/cmenvaud/565/565.pdf

29. Gough, I. Heat, Greed and Human Need: Climate Change, Capitalism and Sustainable Wellbeing (Elgar, 2017).

30. Lockwood, M. The economics of personal carbon trading. Clim. Policy 10, 447-461 (2010)

31. Drummond, P. \& Ekins, P. Reducing $\mathrm{CO}_{2}$ emissions from residential energy use. Build. Res. Inf. 44, 585-603 (2016).

32. Rosenow, J., Fawcett, T., Eyre, N. \& Oikonomou, V. Energy efficiency and the policy mix. Build. Res. Inf. 44, 562-574 (2016).

33. Whitmarsh, L., Seyfang, G. \& O’Neill, S. Public engagement with carbon and climate change: to what extent is the public 'carbon capable'? Glob. Environ. Change 21, 56-65 (2011).

34. Andersson, D., Lofgren, A. \& Widergerg, A. Attitudes to Personal Carbon Allowances (School of Business, Economics and Law, Univ. Gothenburg, 2011); https://gupea.ub.gu.se/handle/2077/25549

35. Starkey, R. Personal carbon trading: a critical survey. Part 1: equity. Ecol. Econ. 73, 7-18 (2012).

36. IPCC Special Report on Global Warming of $1.5^{\circ} \mathrm{C}$ (eds Masson-Delmotte, V. et al.) (WMO, 2018); http://www.ipcc.ch/report/sr15/

37. Martiskainen, M. et al. Contextualizing climate justice activism: knowledge, emotions, motivations, and actions among climate strikers in six cities. Glob. Environ. Change 65, 102180 (2020).

38. Parth, A.-M., Weiss, J., Firat, R. \& Eberhardt, M. “How dare you!"-the influence of Fridays for Future on the political attitudes of young adults. Front. Polit. Sci. 2, 611139 (2020).

39. Marquardt, J. Fridays for Future's disruptive potential: an inconvenient youth between moderate and radical Ideas. Front. Commun. 5, 48 (2020).

40. Woerdman, E., Couwenberg, O. \& Nentjes, A. Energy prices and emissions trading: windfall profits from grandfathering? Eur. J. Law Econ. 28, 185-202 (2009)

41. Willis, R. Too Hot to Handle? The Democratic Challenge of Climate Change (Bristol Univ. Press, 2020).

42. Emissions Gap Report 2020 (UNEP, 2020); https://www.unep.org/ emissions-gap-report-2020

43. Akinbi, A., Forshaw, M. \& Blinkhorn, V. Contact tracing apps for the COVID-19 pandemic: a systematic literature review of challenges and future directions for neo-liberal societies. Heal. Inf. Sci. Syst. 9, 18 (2021) 
44. Shahroz, M. et al. COVID-19 digital contact tracing applications and techniques: a review post initial deployments. Transp. Eng. 5, 100072 (2021).

45. Kapa, S., Halamka, J. \& Raskar, R. Contact tracing to manage COVID- 19 spread-balancing personal privacy and public health. Mayo Clin. Proc. 95, 1320-1322 (2020).

46. Sharma, T. \& Bashir, M. Use of apps in the COVID-19 response and the loss of privacy protection. Nat. Med. 26, 1165-1167 (2020).

47. Darby, S. J. The role of smart meters in carbon management. Carbon Manage. 4, 111-113 (2013)

48. Sullivan, R. K. et al. Smartphone apps for measuring human health and climate change co-benefits: a comparison and quality rating of available apps. JMIR mHealth uHealth 4, e135 (2016).

49. Nunes, I. \& Jannach, D. A systematic review and taxonomy of explanations in decision support and recommender systems. User Model. User Adapt. Interact. 27, 393-444 (2017).

50. Zawacki-Richter, O., Marín, V. I., Bond, M. \& Gouverneur, F. Systematic review of research on artificial intelligence applications in higher educationwhere are the educators? Int. J. Educ. Technol. High. Educ. 16, 39 (2019).

51. Park Woolf, B. Building Intelligent Interactive Tutors: Student-Centered Strategies for Revolutionizing E-Learning (Elsevier, 2009).

52. Fuso Nerini, F. et al. Mapping synergies and trade-offs between energy and the Sustainable Development Goals. Nat. Energy 3, 10-15 (2018).

53. Fawcett, T. Personal carbon trading in different national contexts. Clim. Policy 10, 339-352 (2010).

54. Woerdman, E. Path-dependent climate policy: the history and future of emissions trading in Europe. Eur. Environ. 14, 261-275 (2004).

55. OECD in Science, Technology and Industry Outlook 2010 251-279 (OECD, 2010)

56. Gunningham, N. \& Sinclair, D. Regulatory pluralism: designing policy mixes for environmental protection. Law Policy 21, 49-76 (1999).

57. Kern, F., Kivimaa, P. \& Martiskainen, M. Policy packaging or policy patching? The development of complex energy efficiency policy mixes. Energy Res. Soc. Sci. 23, 11-25 (2017)

58. Howlett, M. \& Rayner, J. in Handbook of Policy Formulation (eds Howlett, M. et al) 112-128 (Edward Elgar, 2017).

59. Dobbins, A., Fuso Nerini, F., Deane, P. \& Pye, S. Strengthening the EU response to energy poverty. Nat. Energy 4, 2-5 (2019).
60. Véliz, C. Privacy and digital ethics after the pandemic. Nat. Electronics 4 , 10-11 (2021).

61. Thumim, J. \& White, V. Distributional Impacts of Personal Carbon Trading: A Report to the Department for Environment, Food and Rural Affairs (DEFRA, 2008); https://www.gov.uk/government/organisations/department-forenvironment-food-rural-affairs/about/research (2008).

62. Li, J., Fan, J., Zhao, D. \& Wang, S. Allowance price and distributional effects under a personal carbon trading scheme. J. Clean. Prod. 103, 319-329 (2015).

63. Uusitalo, E., Kuokkanen, A., Uusitalo, V., von Wright, T. \& Huttunen, A. Personal carbon trading in mobility may have positive distributional effects. Case Stud. Transp. Policy 9, 315-323 (2021).

64. Parag, Y. \& Strickland, D. Personal carbon trading: a radical policy option for reducing emissions from the domestic sector. Environment 53, 29-37 (2011).

\section{Acknowledgements}

F.F.N. acknowledges the KTH Climate Action Centre for providing a platform for this research. T.F. acknowledges funding from UK Research and Innovation via the Centre for Research into Energy Demand Solutions (grant agreement number EP/R035288/1)

\section{Author contributions}

F.F.N. led the manuscript conception, design, writing and revisions. T.F., Y.P. and P.E. all contributed to the design of the work, content development, writing and revisions.

\section{Competing interests}

The authors declare no competing interests.

\section{Additional information}

Correspondence should be addressed to F.F.N.

Peer review information: Nature Sustainability thanks Jing Wan and Edwin Woerdman for their contribution to the peer review of this work.

Reprints and permissions information is available at www.nature.com/reprints.

Publisher's note Springer Nature remains neutral with regard to jurisdictional claims in published maps and institutional affiliations.

(c) Springer Nature Limited 2021 